\title{
THERMAL STABILITY OF AA1050 ALUMINUM ALLOY AFTER EQUAL CHANNEL ANGULAR PRESSING
}

\begin{abstract}
The annealing behavior of AA1050 aluminum alloy deformed by equal-channel angular pressing (ECAP) was studied experimentally. The material was subjected to extrusion through die with channels intersecting at an $90^{\circ}$ angle. Samples were pressed for up to 8 passes using route $\mathrm{B}_{\mathrm{C}}$, then cut into slices and subsequently annealed for 1 hour at temperatures from $100^{\circ} \mathrm{C}$ to $350^{\circ} \mathrm{C}$. Hardness measurements were performed on each slice. Microstructure of material was analyzed in the longitudinal section by means of Electron Backscatter Diffraction system in a scanning electron microscope (EBSD/SEM). From the obtained sets of Kikuchi diffraction patterns orientation maps and Image Quality maps were determined. Grain size, disorientation distributions and crystallographic texture were also estimated. ECAP caused significant improvement of hardness, with stabilization after 4 passes. Refinement of microstructure was obtained with the increasing amount of passes. Material properties were stable during annealing at temperatures lower than $150^{\circ} \mathrm{C}$. Annealing at higher temperatures caused a decrease in hardness corresponding to an increase of the grain size.

Keywords: ECAP, Hardness, EBSD, Texture, Recrystallization
\end{abstract}

\section{Introduction}

One of the main purposes of materials science at present time is producing advanced materials which satisfy still growing requirements. Mechanical properties can be improved by refinement of grain size [1,2]. Research carried out on that issue led to development of many methods of severe plastic deformation (SPD), in which the most known are the equal channel angular pressing (ECAP) [3], high pressure torsion (HPT) [4] and accumulate roll bonding (ARB) [5]. These methods provide accumulation of deformation leaving unchanged initial size and shape of the sample and (theoretically) could be continued for an infinite number of passes. ECAP can be carried out using several various routes. These are achieved by rotation of the specimen between passes providing shear in different planes, which affects the microstructure of material and also its properties [6].

Research carried out in the recent years have verified the influence of ECAP on microstructure and mechanical properties in various metallic materials. Yield strength, ultimate tensile strength and hardness of various aluminum alloys e.g. $[9,10]$ as well as $\mathrm{Cu}, \mathrm{Ti}$, and steels e.g. [11-13] processed by ECAP were significantly improved. Recently, mechanical properties of AA1050 subjected to ECAP and less known KoBo method were compared [14]. Microstructural investigetions of cemmercial pure aluminum deformed by KoBo method are saparate subject. Current work is focused on the influence of annealing at different temperatures on the mechanical properties-(hardness) and microstructure of technically pure aluminum deformed by
ECAP. Reports concerning thermal stability of materials are rare, even though renewal processes of severely deformed structures such as recovery and recrystallization have essential effect on properties of the materials. Moreover a lot of applications of metallic materials are related to their performance at increased temperatures. Understanding of thermal phenomena and evaluation of thermal stability is therefore essential for preserving defined functionality of a material.

\section{Experimental procedures}

Material used in the research was AA1050 aluminum, which chemical composition measured by spark emission spectroscopy Bruker Q4 Tasman is presented in Table 1. The composition was positively confronted with the standard $P N-E N$ 573-3:1998. The AA1050 was received in form of pressed rods, and machined to $10 \mathrm{~mm} 10 \mathrm{~mm} \times 55 \mathrm{~mm}$ samples. The samples were then annealed for 8 hours at $500^{\circ} \mathrm{C}$, and cooled with furnace to room temperature in order to obtain homogenous microstructure. For ECAP experiments die channels intersected at $\varphi=90 \mathrm{deg}$, with outer arc angle equal to $\psi=20 \mathrm{deg}$ (Fig. 1a) were applied. The true strain was calculated using formula presented in [16]:

$$
\varepsilon_{N}=N\left[\frac{2 \times \cot \left(\frac{\phi}{2}+\frac{\psi}{2}\right)+\psi \times \operatorname{cosec}\left(\frac{\phi}{2}+\frac{\psi}{2}\right)}{\sqrt{3}}\right]
$$

\footnotetext{
* INSTITUTE OF METALLURGY AND MATERIALS SCIENCE, POLISH ACADEMY OF SCIENCE, REYMONTA 25, 30-059 CRACOW, POLAND

** INSTITUTE OF MATERIALS SCIENCE, CRACOW UNIVERSITY OF TECHNOLOGY, AL. JANA PAWŁA II 37, 31-864 CRACOW, POLAND 
Chemical composition of AA1050 from standard PN-EN 573-3:1998 and measured by spark emission spectroscopy Brucker Q4 Tasman

\begin{tabular}{|l|c|c|c|c|c|c|c|c|}
\hline \multicolumn{1}{|c|}{ Chemical composition } & Al [\%] & Fe [\%] & Si [\%] & Cu [\%] & Mn [\%] & Mg [\%] & Zn [\%] & Ti [\%] \\
\hline AA 1050 from standard PN-EN 573-3:1998 & $\geq 99.50$ & $\leq 0.40$ & $\leq 0.25$ & $\leq 0.05$ & $\leq 0.05$ & $\leq 0.05$ & $\leq 0.07$ & $\leq 0.05$ \\
\hline AA 1050 measured & 99.54 & 0.304 & 0.066 & 0.004 & $<0.002$ & 0.008 & 0.005 & 0.008 \\
\hline
\end{tabular}

a)

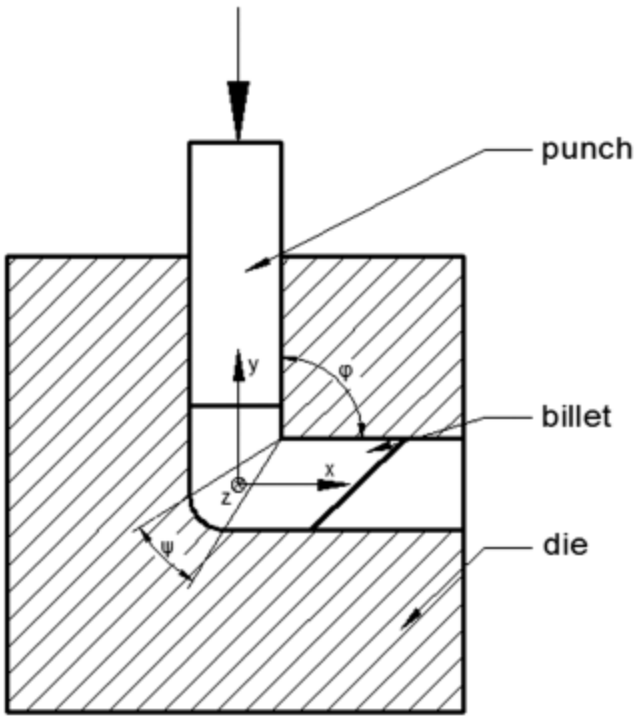

b)

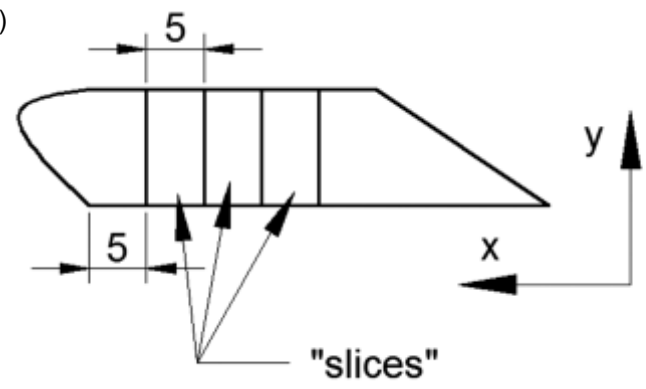

c)

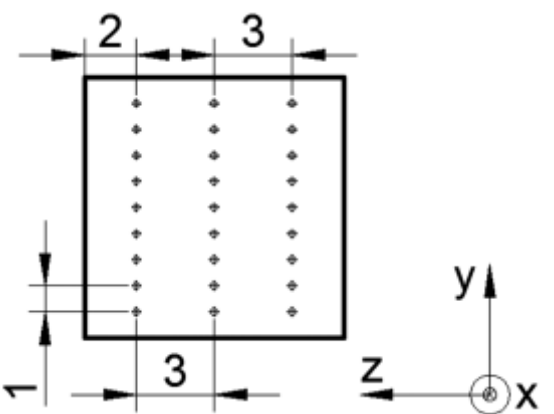

Fig. 1. (a) Scheme of ECAP die, (b) sample preparation for hardness measurements-slicing, (c) scheme of hardness measurements on an example of a slice

For the die described above, true strain equals 1.916. Graphite grease was used as a lubricant. ECAP was performed at room temperature for up to 8 passes. Billet was pushed out from the die by the following billet.

After deformation by ECAP, material was sliced to $10 \mathrm{~mm}$ $\times 10 \mathrm{~mm} \times 5 \mathrm{~mm}$ specimens (Fig. 1c) and annealed for 1 hour at temperatures from $100^{\circ} \mathrm{C}$ to $350^{\circ} \mathrm{C}$, with step $50^{\circ} \mathrm{C}$. Slices were cut from central part of the billet where material is mainly homogenous. Hardness was measured using INNOVATEST microhardness tester type 423A. Measurements were performed under load of $1 \mathrm{~kg}$ on plane $\mathrm{z}-\mathrm{y}$, along three lines parallel to the $\mathrm{y}$ axis, in nine points on each line (Fig. 1d). From 27 received values the mean hardness and deviation with 0.95 confidence coefficient were calculated. Microstructure of extruded material was observed in the longitudinal section by means of Electron Backscatter Diffraction (EBSD) in scanning electron microscope FEI Quanta 3D FEGSEM under conditions: accelerating voltage 20 $\mathrm{kV}$, beam current $8 \mathrm{nA}$, camera binning $4 \times 4$ and speed mapping $\sim 30$ frame per second. Samples for EBSD measurements were grinded using sandpapers up to 5000 and polished using diamond paste up to $1 \mu \mathrm{m}$. Additionally, specimens were electro-polished using mixture of perichloric acid and ethanol for 7 seconds, to obtain perfect mirror-like surface. Microstructure characterization was performed on plane $x-y$, standard orientation maps (Fig. 1b), and Image Quality (IQ) maps were analyzed. The maps were constructed based on measured sets $\left(>10^{6}\right)$ of Kikuchi diffraction patterns using software OIM ANALYSIS 7.2 by EDAX. After measurement data was cleaned up using grain dilatation, with grain tolerance angle $-2^{\circ}$ and minimum grain size -2 pixels. The procedure was applied to minimalize wild spike points (isolated misindexed points) in the maps. . Analysis of orientation was performed to obtain information about parameters such as grain sizes, disorientations distributions and crystallographic textures. Orientation maps were colored according to IPF coloring scheme for the $\mathrm{x}$ direction (extrusion direction). In turn IQ maps depict differences in the lattice defect density both between the separate grains and between different regions within single grain. Utilization of field emission gun (FEG) in SEM enabled high spatial 
resolution of EBSD measurement, sufficient to visualize grain substructure indicated by low angle disorientation segments.

The disorientation may be described mathematically in several ways. The "natural" is the description by the rotation axis $r$ and rotation angle $\omega$. Due to the crystallographic symmetry, the disorientation description is not univocal. The smallest of the rotation angles $\omega$ is called the angle of disorientation $[16,17]$. Disorientation angle distributions were presented as correlated, uncorrelated and random. Correlated distribution show disorientations between each grain and its neighbors. Uncorrelated compares disorientations between grain and all crystallites obtained on orientation map. Random distribution is uncorrelated one and shows the disorientation distribution for a purely random distribution of grain orientations (lack of texture). Grain size was determined as a diameter of a circle of the same area as the grain. Textures were presented in the form of pole figures (001), (101), (111).
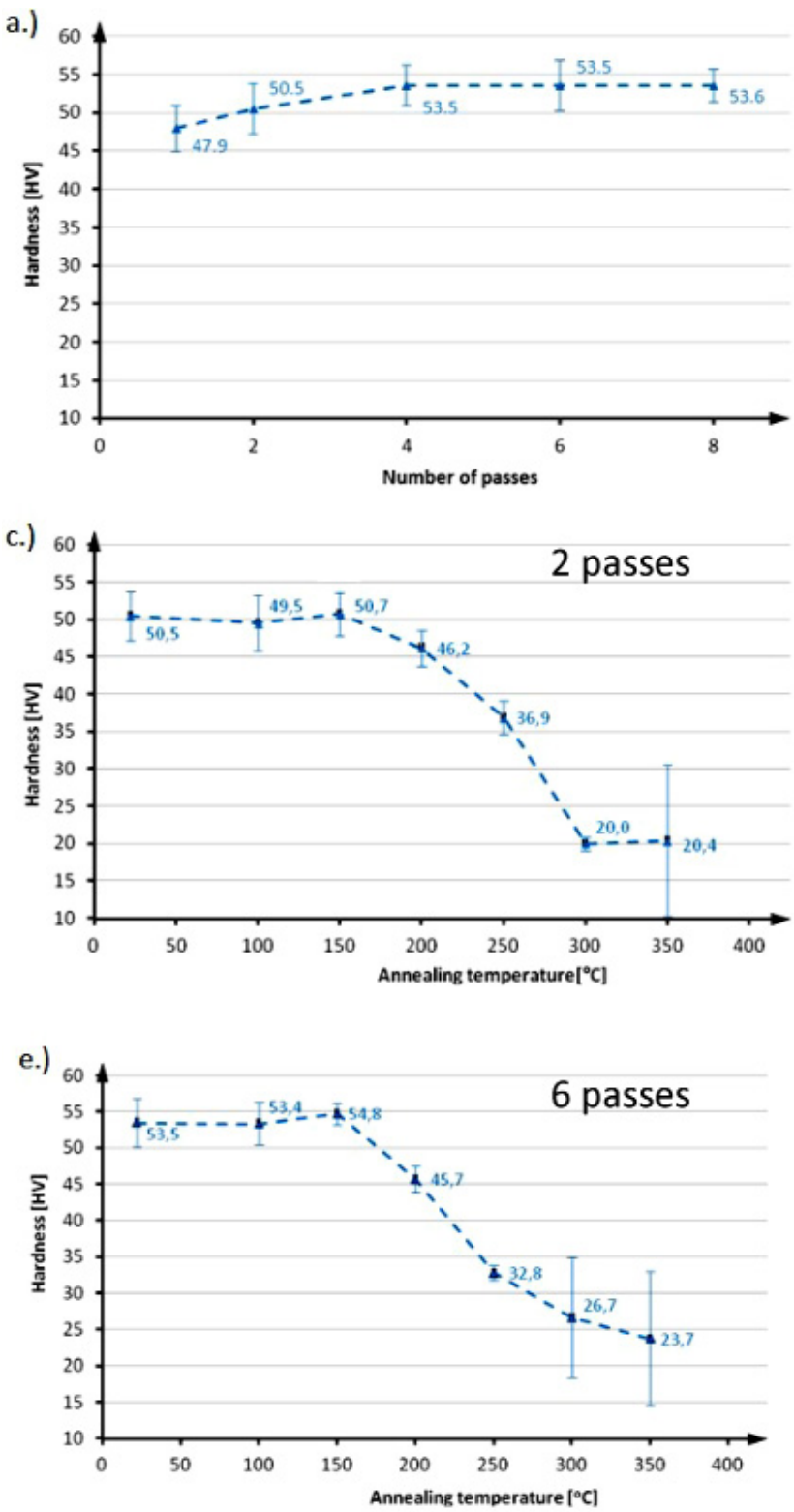

\section{Results}

Figure 2a shows changes in hardness of the AA 1050 samples processed by ECAP up to 8 passes. Hardness of the initial, homogenized at $500^{\circ} \mathrm{C}$ material equaled $20 \mathrm{HV}$. This value was already improved after one pass. Further increasing of the strain up to four passes was associated with increase of hardness. After the fourth pass hardness was stabilized at the level of about 53.5 HV. Succeeding (Figs. 2b-f) show changes of material hardness after annealing for one hour after 1,2,4,6 and 8 passes at temperature range from $100^{\circ} \mathrm{C}$ to $350^{\circ} \mathrm{C}$. After one pass, mechanical properties (hardness) remained in similar value up to $200^{\circ} \mathrm{C}$. Significant decrease of hardness was observed only above that temperature. In turn material after two and more passes was thermally stable up to $150^{\circ} \mathrm{C}$. In the most samples annealed at $150^{\circ} \mathrm{C}$ even slight increase of hardness was observed. Above that temperature sharp drop of mechanical properties occurred for
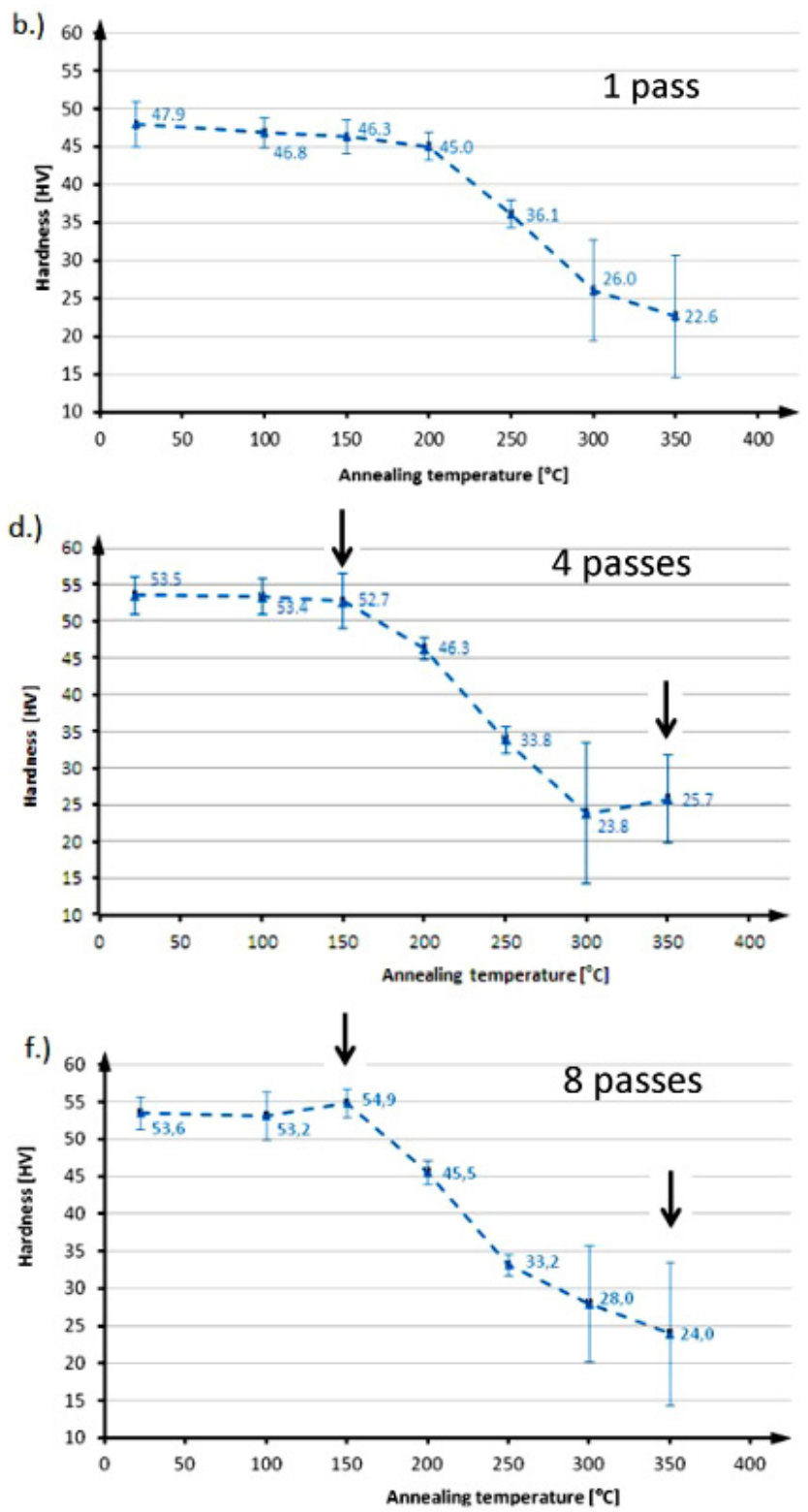

Fig. 2. (a) Hardness as a function of number of passes and (b-f) as a function of annealing temperature for material previously deformed by ECAP (b) 1, (c) 2, (d) 4, (e) 6, (f) 8 passes. Black arrows indicate samples selected for further research 
all samples. The lowest values of hardness were mostly found for samples annealed at $350^{\circ} \mathrm{C}$. Results obtained for material annealed at $350^{\circ} \mathrm{C}$ were close to that of initial material. It should be noted that hardness measurements of material annealed at temperatures $300^{\circ} \mathrm{C}$ and $350^{\circ} \mathrm{C}$ can be saddled with larger errors caused by the presence of lower and higher hardness areas in the material simultaneously. For microstructure characterization samples (marked in Fig. 2 by black arrows): after four and eight passes, annealed at $150^{\circ} \mathrm{C}$ and $350^{\circ} \mathrm{C}$ were selected.

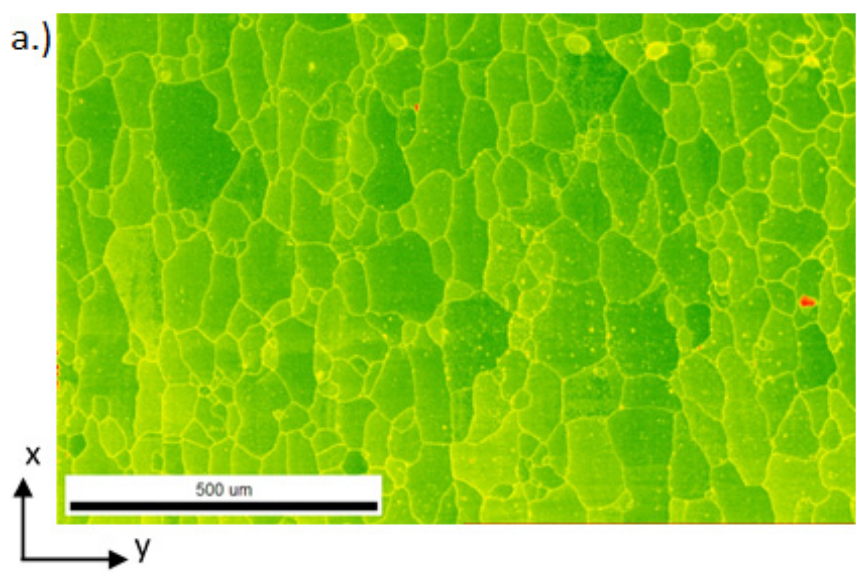

c.)

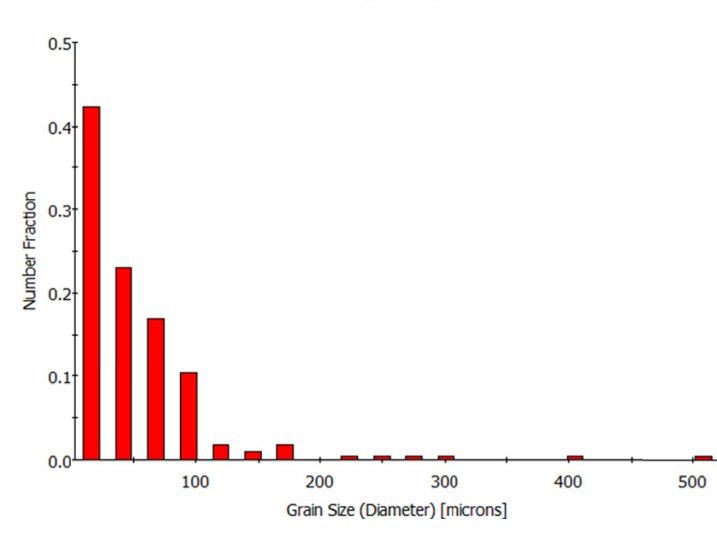

An average grain size, fraction of low (LAGBs) and high angle grain boundaries (HAGBs) of initial material, samples deformed by ECAP and subsequently annealed at various temperatures are summarized in Table 1. Average grain size after homogenizing annealing (initial material) equaled $50.79 \mu \mathrm{m}$, and dropped to about $1 \mu \mathrm{m}$ after four passes, as well as after eight passes despite subsequent annealing at $150^{\circ} \mathrm{C}$ for $1 \mathrm{~h}$. The smallest grain size was obtained after eight passes. This effect remained even after annealing at $350^{\circ} \mathrm{C}$. Significant dispersion
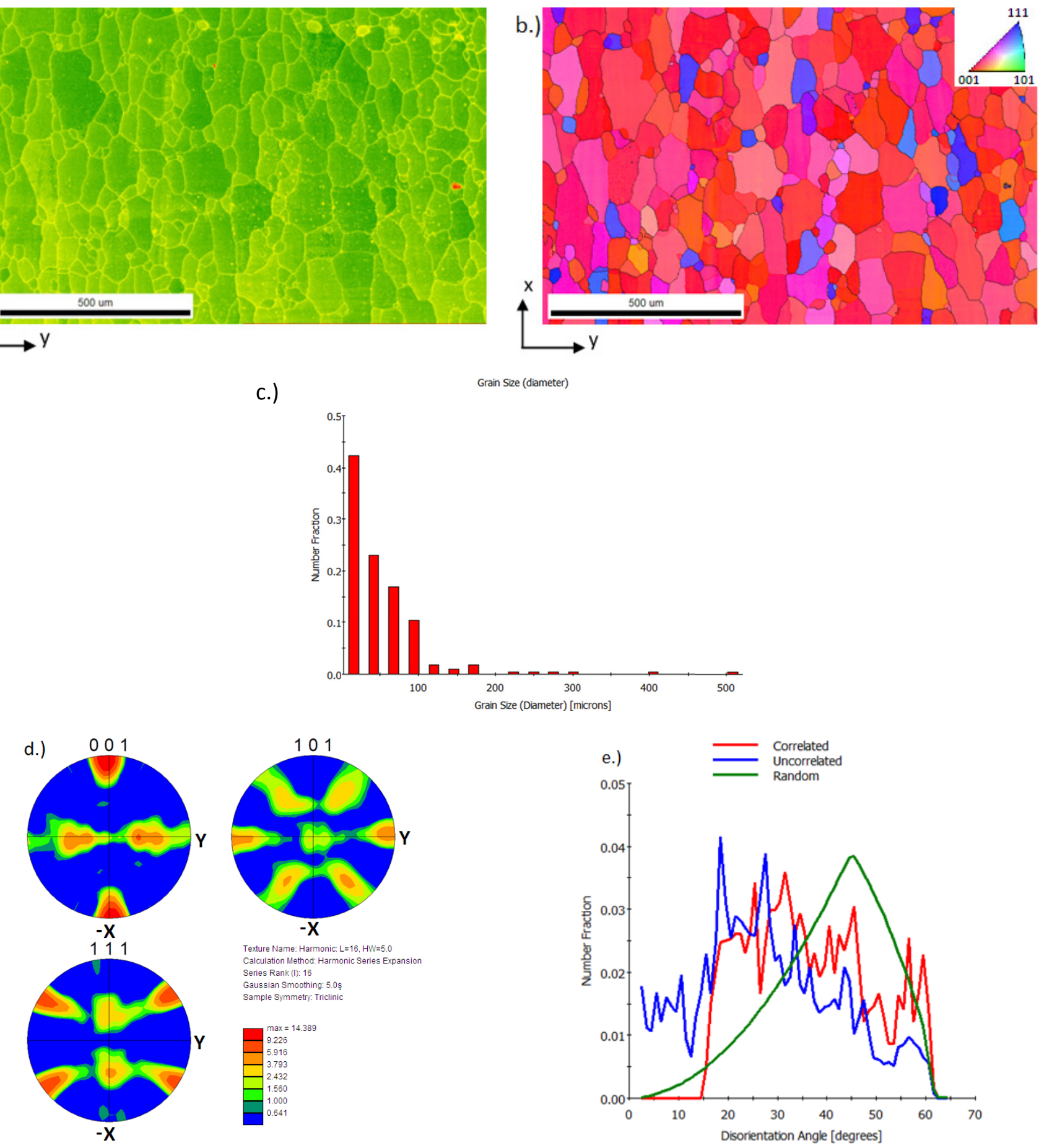

Fig. 3. (a) Example image quality and (b) IPF map of material after homogenizing annealing at $500^{\circ} \mathrm{C}$. (c) Grain size (diameter) in function of area fraction for same sample. (d) (001), (101), (111) pole figures determined by EBSD technique. The plane of pole figures projection is parallel to the longitudinal plane of the billet. (e) Disorientations angle distributions obtained from the same sample (figure based on pixel to pixel disorientations with angles exceeding $15^{\circ}$ ) 
of the grain size distribution is noted, thus average grain sizes and standard deviation values are similar (Tab. 2). LAGBs are associated with disorientations of angle from $2^{\circ}$ to $15^{\circ}$, while HAGBs with disorientations of angle $>15^{\circ}$. In the deformed state, fraction of LAGBs was higher for samples after lower deformation (4 passes), while in recrystallized state, reverse results were obtained. Fig. 3 presents results for sample after homogenizing annealing in initial state. Equiaxed grains were large, with diameter from $10 \mu \mathrm{m}$ up to even $500 \mu \mathrm{m}$. IQ map suggested that microstructure contain rather low amount of crystal lattice defects. Orientation map indicated an occurrence of cube $\{100\}<001>$ texture, which was also confirmed by pole figures where two nearly symmetrical positions of this orientation were clearly visible. Disorientation angle distribution did not reveal any substructure. Correlated and uncorrelated distributions run similarly, which suggests that the microstructure (more precisely distribution of grain boundaries) is only texture dependent. Fig. 4a,b shows the IQ maps of AA1050 subjected to various
ECAP conditions and then annealed at $150^{\circ} \mathrm{C}$ for 1 hour. Yellow - red colors correspond to areas where the density of crystal lattice defects was high. Green indicate places with low density of defects. It is clear that number of lattice defects increased significantly in comparison to the initial state. Microstructure after four passes is composed of elongated grains, Fig. 4c. Sample subjected to higher deformation consists of more equiaxed grains. In Fig. 4c most of crystallites are oriented with direction [111] parallel to the extrusion direction, however areas where direction [100] is parallel to the extrusion direction are also visible. In the case of sample after 8 passes it was difficult to determine dominant direction (Fig. 4d) Increasing number of passes caused grain refinement, Fig. 5a,b. After four passes grain size varied from bellow 1 up to $10 \mu \mathrm{m}$, while after eight passes grains larger than $6 \mu \mathrm{m}$ did not occur. Pole figures corresponding to the orientation maps are shown in Fig. 5c,d. After four passes, they indicate an occurrence of A-type shear texture with the fiber $\{11 \overline{1}\}<\mathrm{uvw}>$, while after eight passes only A-type shear
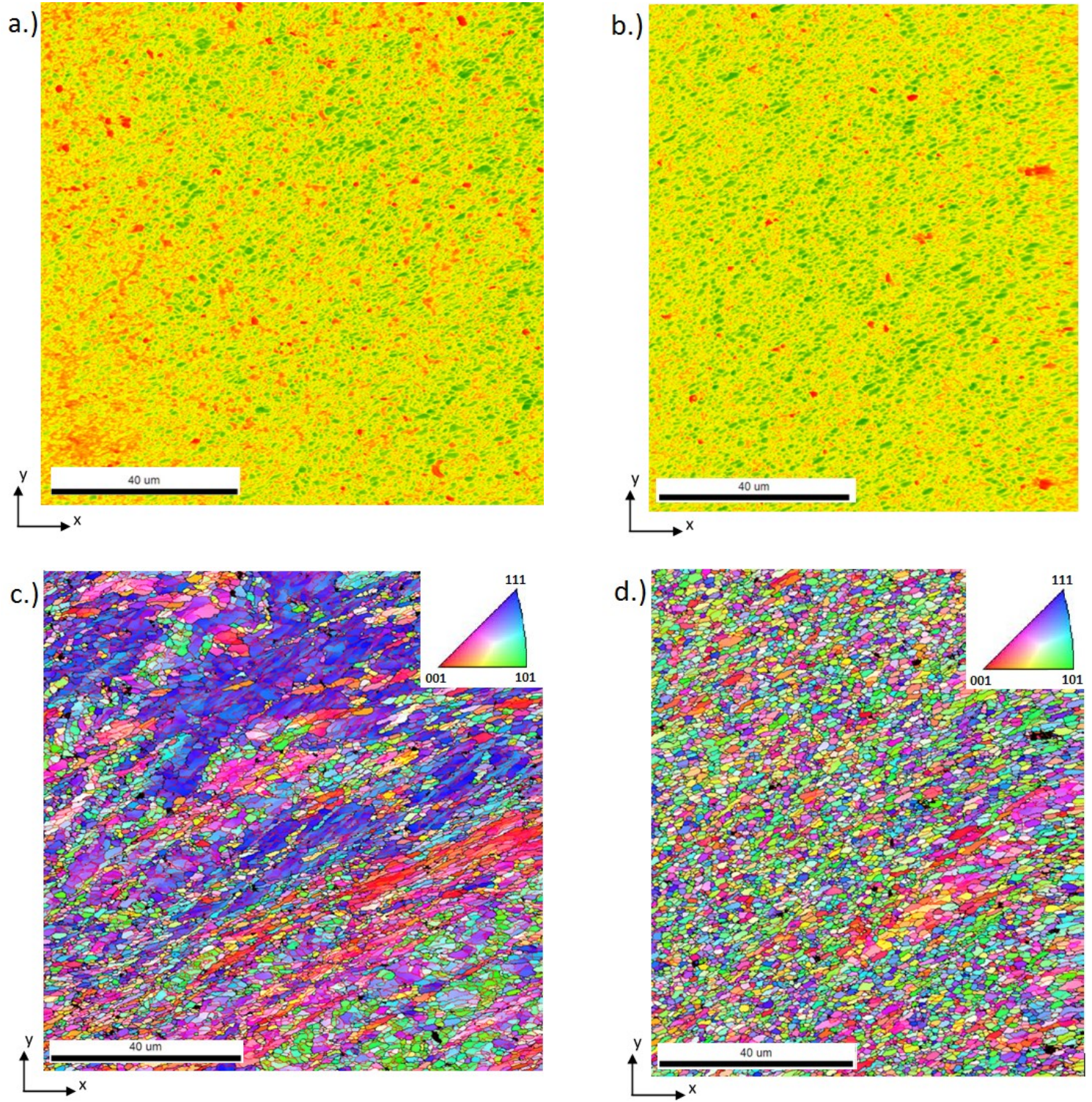

Fig. 4. (a,b) Example image quality maps of annealed AA1050 at $150^{\circ} \mathrm{C}$ for 1 hour, previously subjected to four and eight passes through ECAP die, respectively. (c,d) Example IPF maps of same samples 


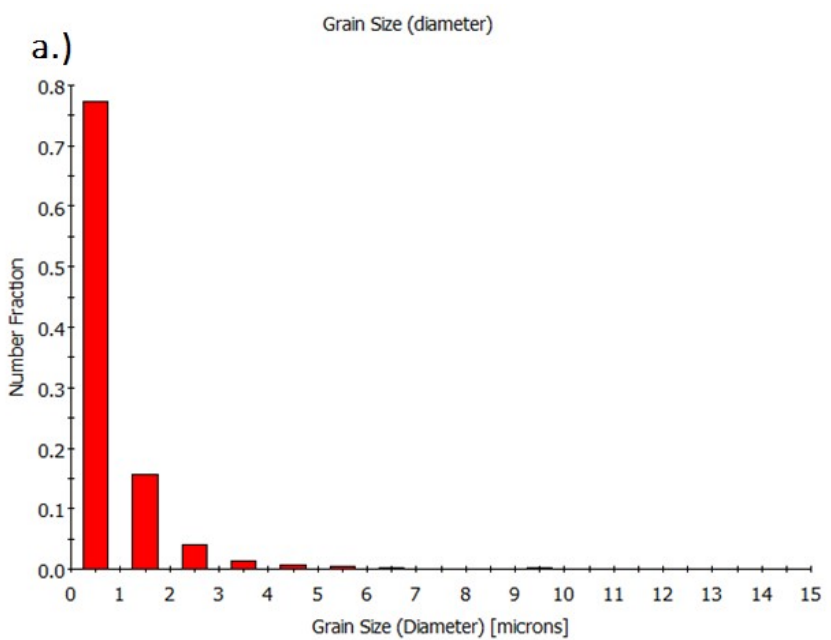

b.)

Grain Size (diameter)

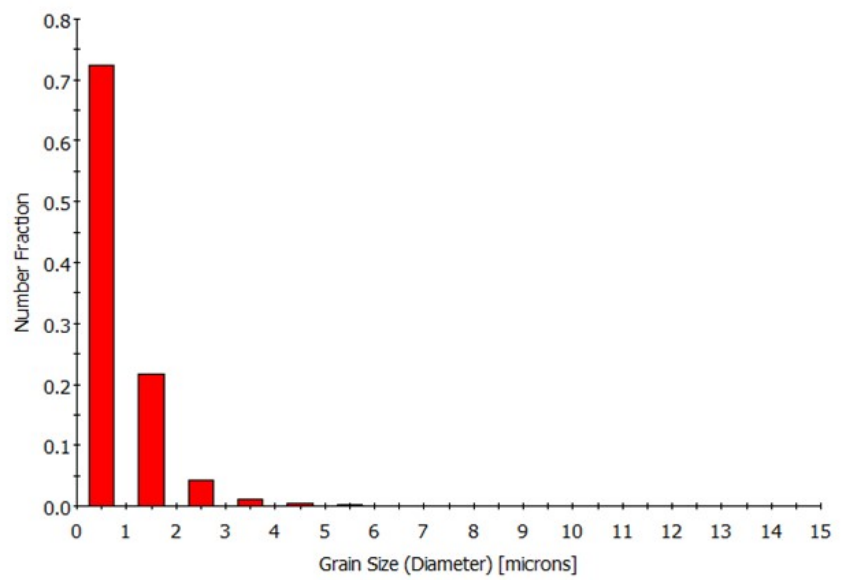

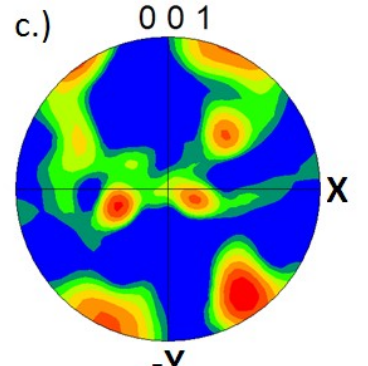
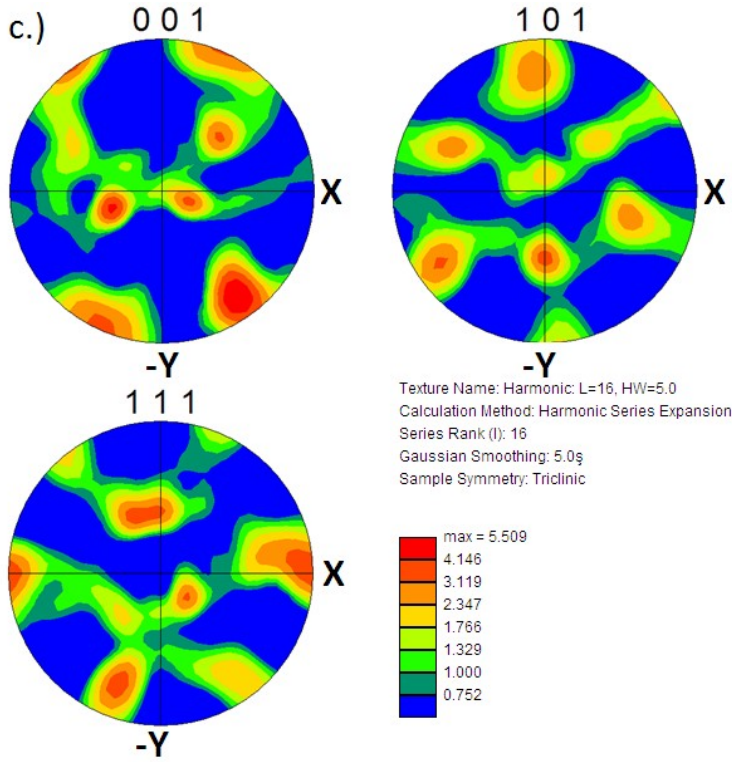

Texture Name: Harmonic $L=16, H W=50$ Calculation Method: Harmonic Series Expansion Series Rank (1): 16

Gaussian Smoothing: 5.0 ș Sample Symmetry: Triclinic
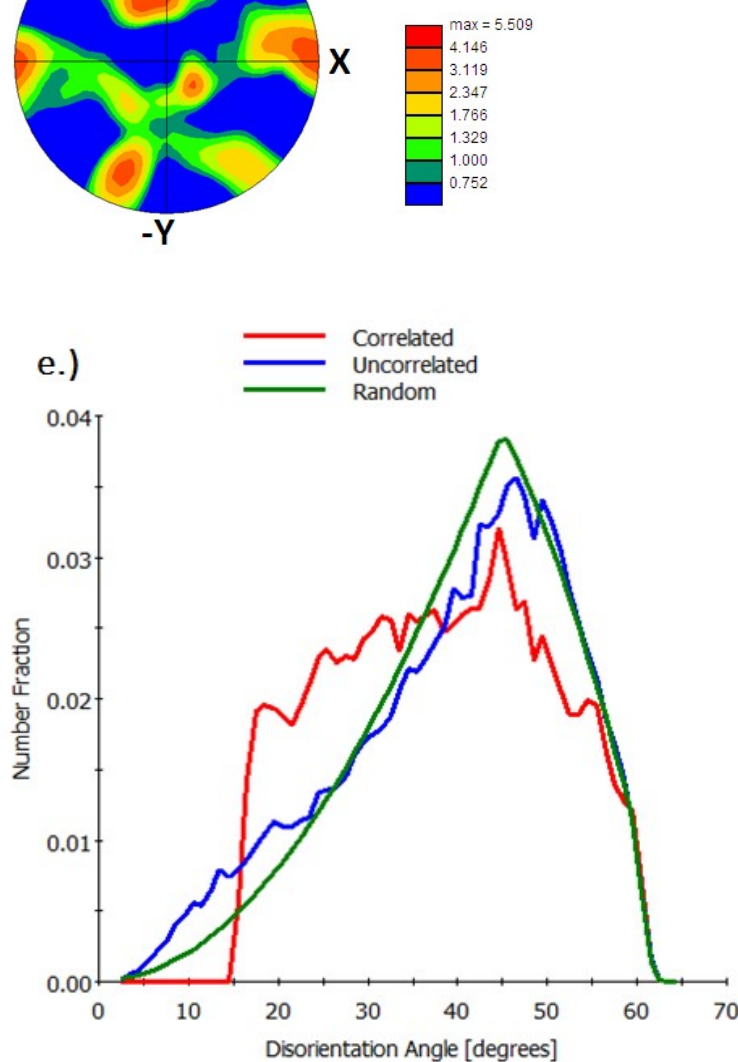

d.)

001
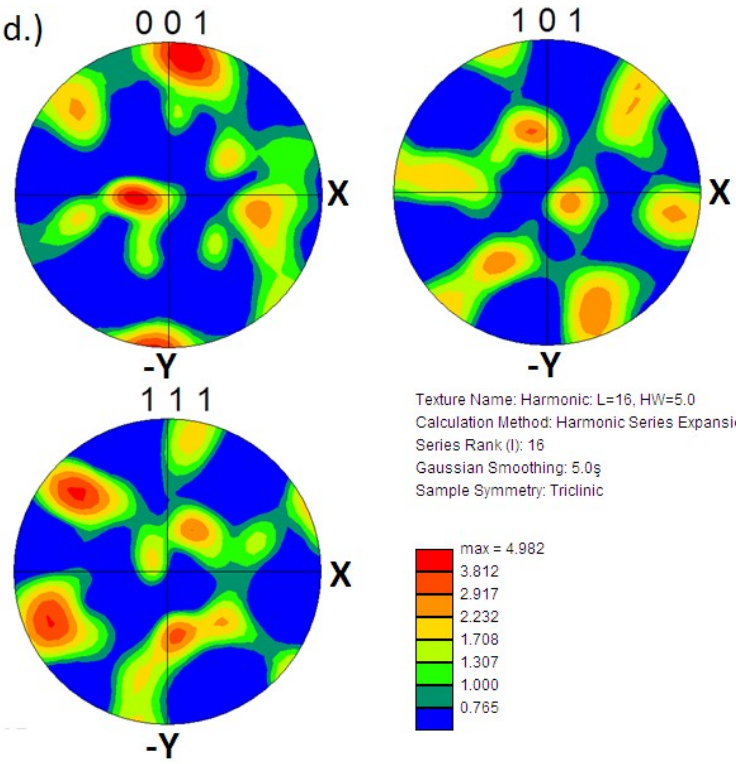

Texture Name: Harmonic: L=16, HW=5.0 Calculation Wethod: Harmonic Series Expansion Series Rank (I): 16 Gaussian Smoothing: 5.0 ș Sample Symmetry: Triclinic
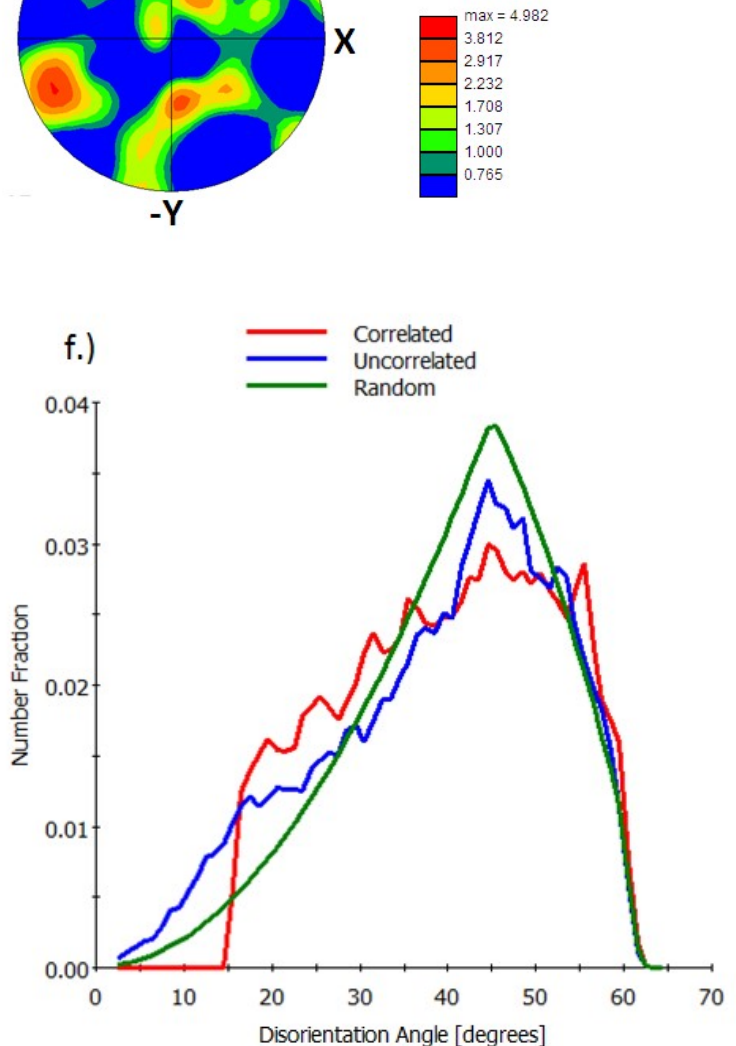

Fig. 5. (a,b) Grain size (diameter) in function of area fraction of annealed AA1050 at $150^{\circ} \mathrm{C}$ for 1 hour, previously subjected to four and eight passes through ECAP die, respectively. (c,d) Corresponding (001), (101), (111) pole figures determined by EBSD technique. The plane of pole figures projection is perpendicular to the $x-y$ plane of the billet. $(e, f)$ Disorientations angle distributions obtained from same sample (figure based on pixel to pixel disorientations with angles exceeding $15^{\circ}$ ) 
TABLE 2

Average grain size of ECAP-ed and annealed material at various conditions and step size used for EBSD measurements

\begin{tabular}{|l|c|c|c|}
\hline \hline \multicolumn{1}{|c|}{ Sample } & $\begin{array}{c}\text { Average grain size with standard } \\
\text { deviation }[\boldsymbol{\mu m}]\end{array}$ & Step size [nm] & $\begin{array}{c}\text { Fraction of low/high angle } \\
\text { boundaries }\end{array}$ \\
\hline Homogenized material & $50.79 \pm 62.59$ & 2000 & $0.268 / 0.732$ \\
\hline $\begin{array}{l}\text { After four passes through ECAP die, annealed } \\
\text { at } 150^{\circ} \mathbf{C} \text { for 1h }\end{array}$ & $0.76 \pm 1.60$ & 70 & $0.475 / 0.525$ \\
\hline $\begin{array}{l}\text { After eight passes through ECAP die, annealed } \\
\text { at } 150^{\circ} \mathbf{C} \text { for 1h }\end{array}$ & $0.73 \pm 0,79$ & 70 & $0.230 / 0.770$ \\
\hline $\begin{array}{l}\text { After four passes through ECAP die, annealed } \\
\text { at } 350^{\circ} \mathbf{C} \text { for 1h }\end{array}$ & $7.70 \pm 7.61$ & 120 & $0.246 / 0.754$ \\
\hline $\begin{array}{l}\text { After eight passes through ECAP die, annealed } \\
\text { at } 350^{\circ} \mathbf{C} \text { for } 1 \mathrm{~h}\end{array}$ & $2.34 \pm 8.33$ & 170 & $0.367 / 0.633$ \\
\hline
\end{tabular}
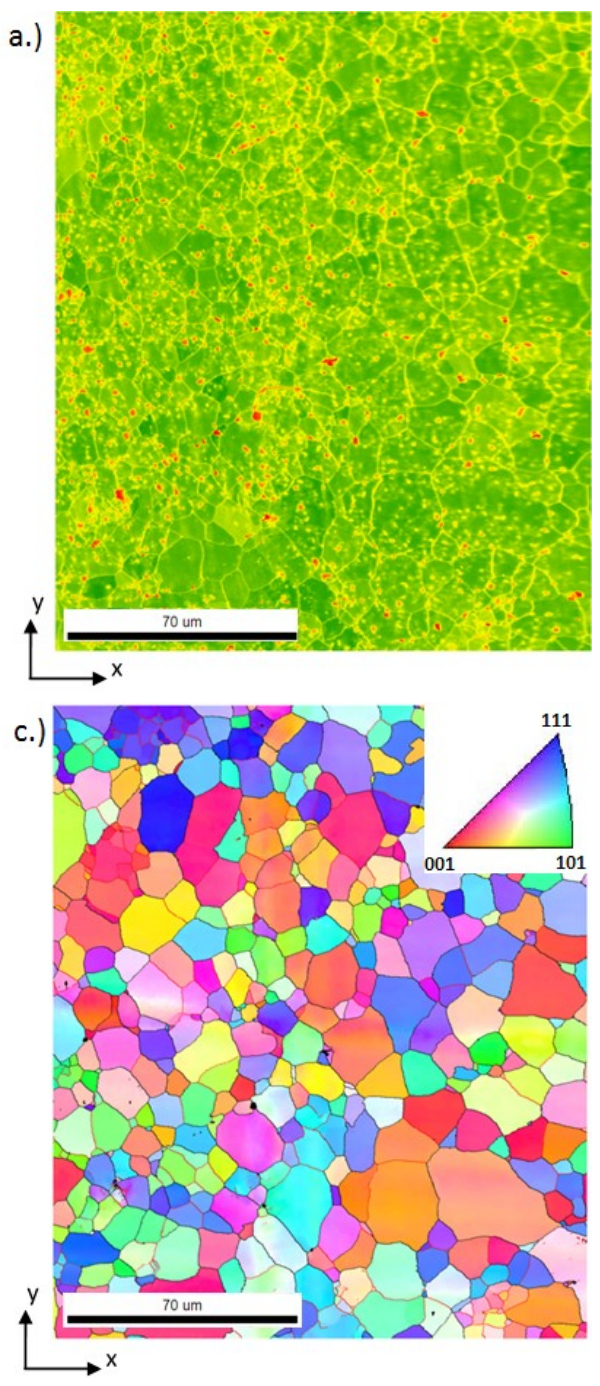
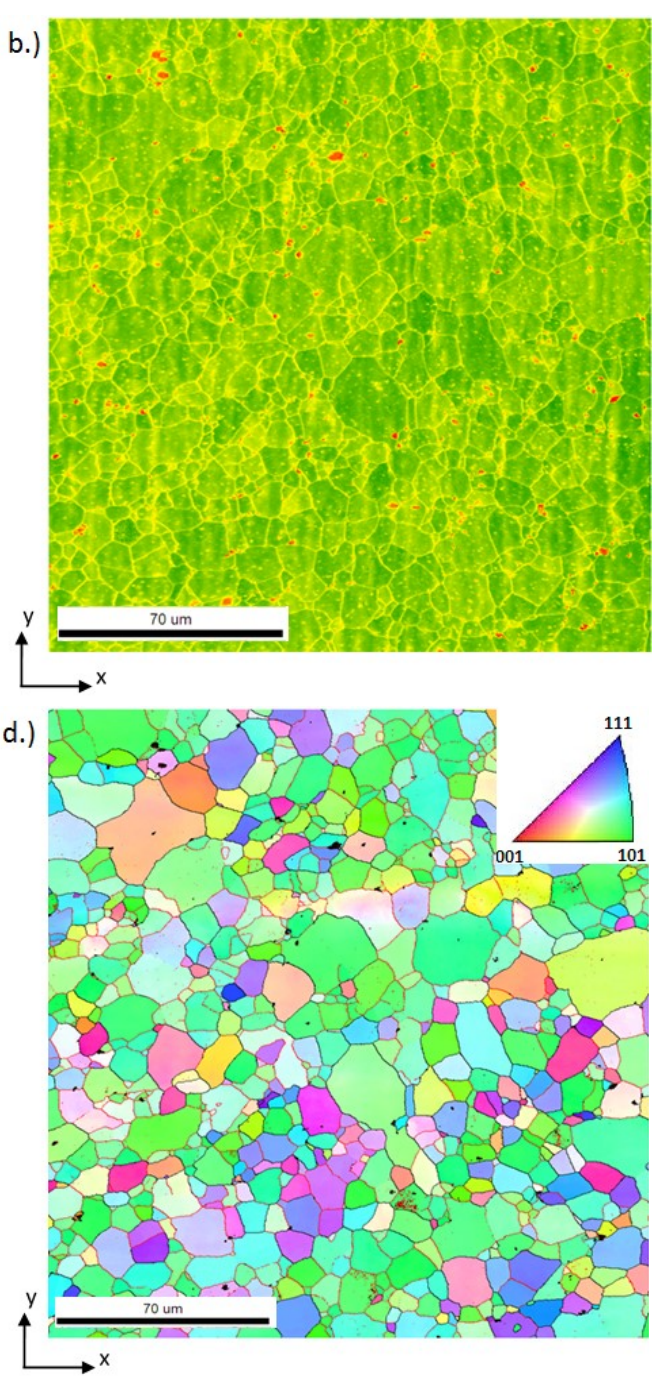

Fig. 6. (a,b) Example image quality maps of annealed AA 1050 at $350^{\circ} \mathrm{C}$ for 1 hour, previously subjected to four and eight passes through ECAP die, respectively $(\mathrm{c}, \mathrm{d})$. Example IPF maps of same samples

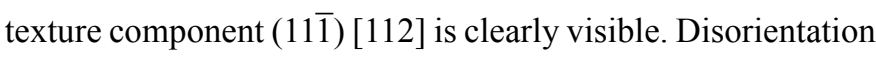
distributions (Fig. 5e,f) showed evident difference between correlated and uncorrelated distributions. This means that distribution of grain boundaries was no more texture dependent. Correlated and uncorrelated distributions became similar for higher deformation mainly due to a decreased share of small disorientations. This indicates that further deformation resulted in transformation of LAGBs into HAGBs and consequently in higher grain refinement. In this case uncorrelated and random distributions became similar, which could be the evidence on texture randomization.

Results obtained after annealing at $350^{\circ} \mathrm{C}$ of the samples deformed in 4 and 8 passes are presented in Figs. 6,7. The IQ maps indicate that in both cases regions of higher lattice defects 

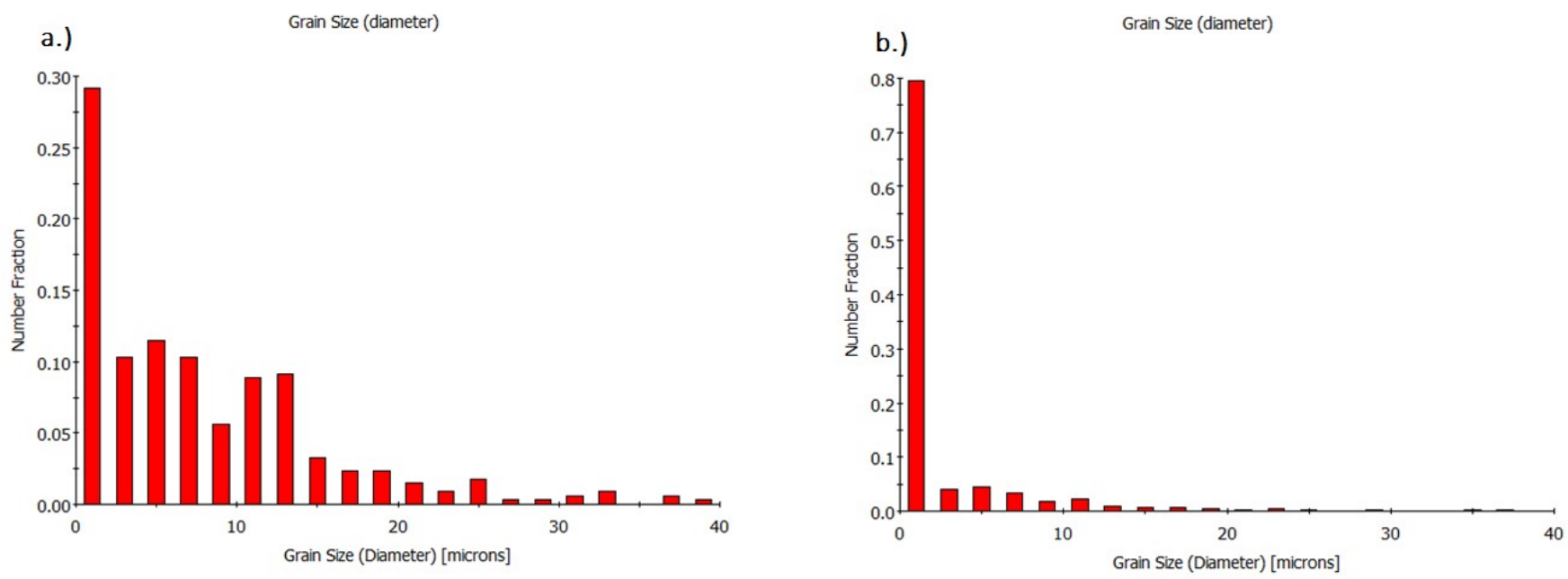

c.)
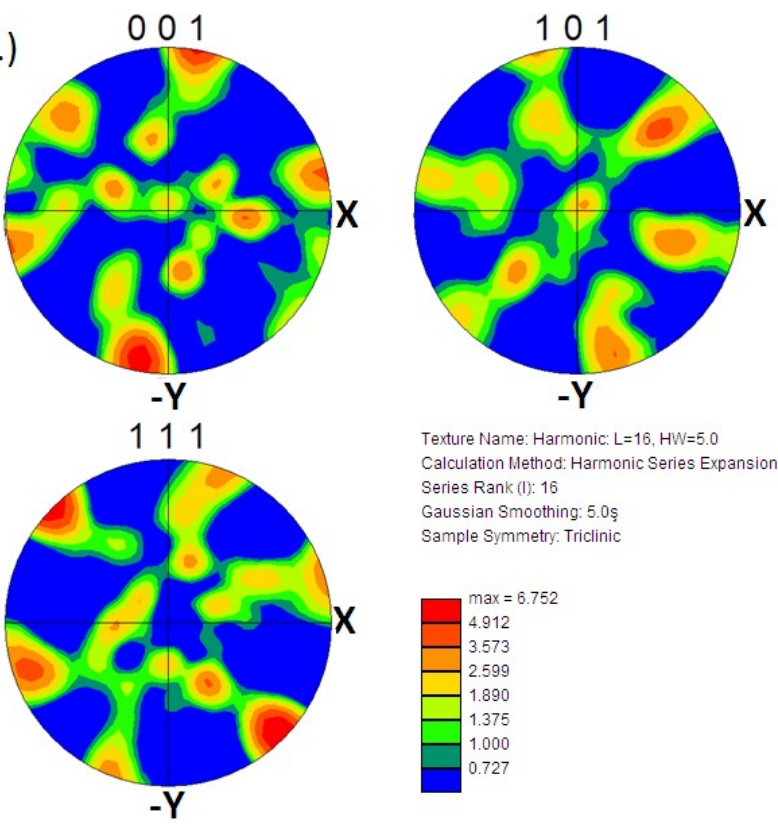

Texture Name: Harmonic: $L=16, H W=5.0$ Calculation IMethod: Harmonic Series Expansion Series Rank (l): 16 Gaussian Smoothing: 5.0 \$ Sample Symmetry: Triclinic
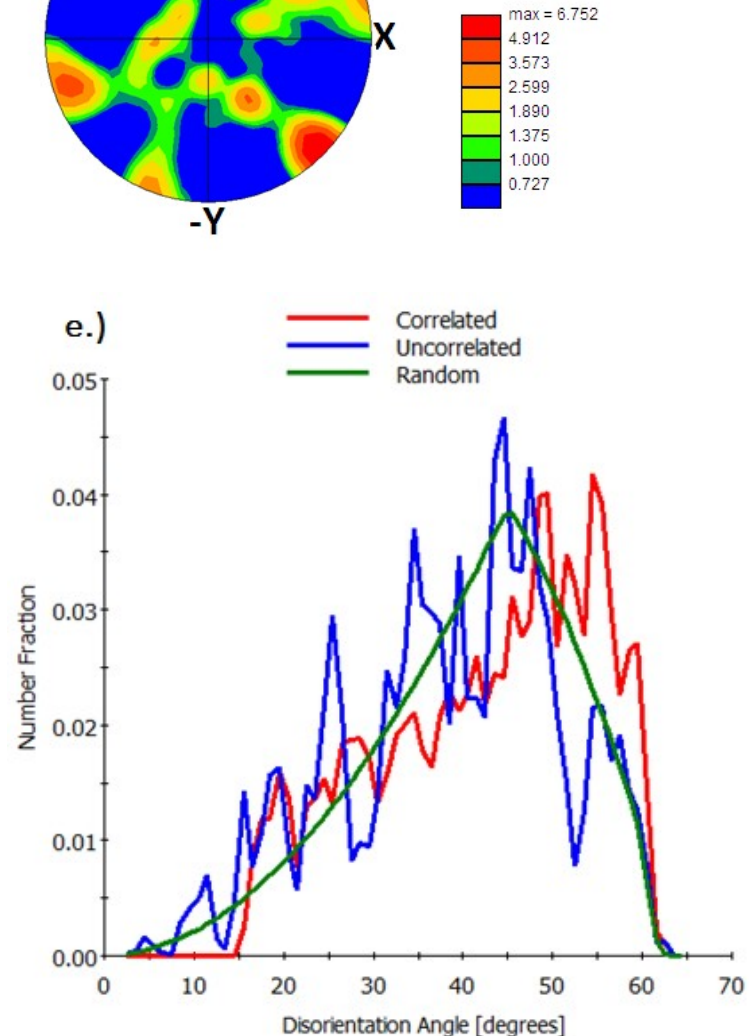

d.)
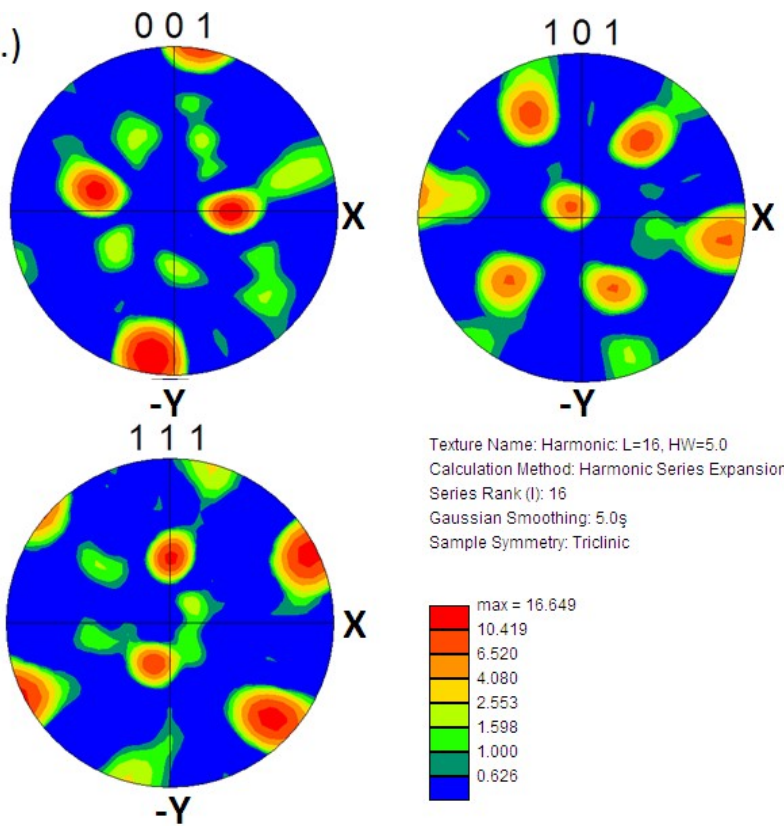

Texture Name: Harmonic: $L=16, H W=5.0$ Calculation Method: Harmonic Series Expansion Series Rank (1): 16 Gaussian Smoothing: 5.0 ș Sample Symmetry: Triclinic
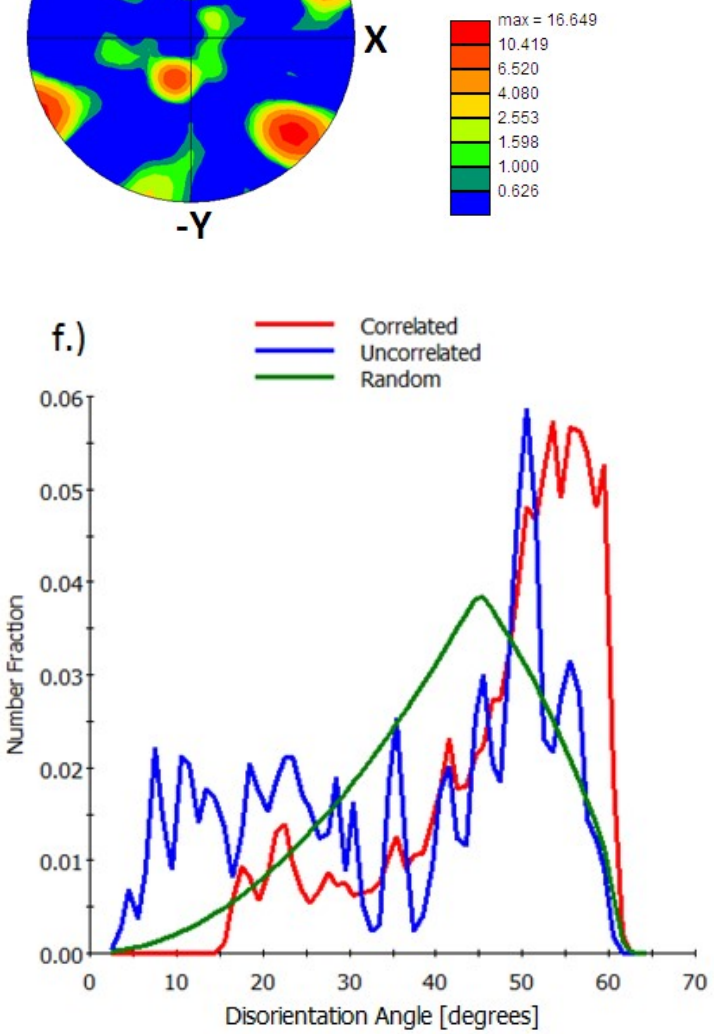

Fig. 7. (a,b) Grain size (diameter) in function of area fraction of annealed AA1050 at $350^{\circ} \mathrm{C}$ for 1 hour, previously subjected to four and eight passes through ECAP die, respectively. (c,d) Corresponding (001), (101), (111) pole figures determined by EBSD technique. The plane of pole figures projection is perpendicular to the $x-y$ plane of the billet. $(e, f)$ Disorientations angle distributions obtained from same sample (figure based on pixel to pixel disorientations with angles exceeding $15^{\circ}$ ) 
density were mostly limited to grain boundaries similarly to the initial state.

For samples previously subjected to higher deformations, extrusion direction is mainly parallel to direction [101], while after lower deformation, there is no preference as observed on orientation maps (Fig. 6c,d). Grain size was mostly below $30 \mu \mathrm{m}$ for both samples. However larger grains occurred occasionally, especially after higher deformation, Fig. 7a,b. That suggests slightly bimodal distribution of grains, with these sized about $40 \mu \mathrm{m}$ and these bellow $30 \mu \mathrm{m}$. The pole figures calculated from orientation maps are shown in Fig. 7c,d. They revealed occurrence of an A-type shear texture with the fiber $\{11 \overline{1}\}<\mathrm{uvw}>$, after four passes, and distinct A-type shear texture component (11 $\overline{1})$ [112], after eight passes (higher maximum intensity). Correlated and uncorrelated disorientation distributions were again similar (Fig. 7e,f). Material previously subjected to lower deformation showed diffuse texture. Poor statistics of disorientation angles obtained from orientation maps, should be noted here. This is due to low quantity of grain boundaries, despite the fact that measured areas were quite large.

\section{Discussion}

ECAP causes significant increase of hardness already after first pass. The continuation of the process leads to further increases of that parameter, however to a lesser extent. Similar behavior was observed for many conventional aluminum alloys subjected to ECAP [18]. Correlation between hardness and grain size is visible, similar to those predicted by Hall-Petch (H-P) relation $[1,2]$. However authors want to note that H-P relation concern yield stress, and not hardness. The hardness - annealing temperature relationship shows three characteristic stages. In the first, values are similar to those obtained after deformation, or in some cases even higher. In the second, straightforward softening of material is visible. Extremely homogenous values of measured hardness is a characteristic feature of this stage. In the third stage, hardness values were vastly inhomogeneous. Achieved results are similar to those before deformation, however appearance of regions with distinctly smaller values were puzzling. High temperature annealing of ECAPed samples might have resulted in occurrence of discontinuous recrystallization process, with the tendency to abnormal growth of grains. However overgrown grains weren't observed on orientation maps. Studies on annealing after deformation $[19,20]$, are indicating that continuous recrystallization is more likely for material subjected to high strain. More recent investigations [21,22] notes that material may undergo discontinuous and continuous recrystallization at same time. It indicates that abnormal nucleation and grain growth occurred only in some favored places, what was also expected in presented work. In paper [21] the authors suggest that favored regions are these with unusual density of HAGBs. Research showed also that renewal processes are activated at temperatures which are significantly influenced by strain degree [7,23]. After one pass of ECAP material seems to be thermally stable up to $200^{\circ} \mathrm{C}$, and after more passes up to $150^{\circ} \mathrm{C}$ which suggests that temperature of the recovery beginning is between $150^{\circ} \mathrm{C}$ and $200^{\circ} \mathrm{C}$. It was also confirmed for AA 1050 alloy by other researches e.g. [8]. Annealing at $150^{\circ} \mathrm{C}$ shows slight increase of hardness. Valiev et al [6] also observed improvement of mechanical properties after annealing at low temperatures (below $200^{\circ} \mathrm{C}$ ) for AA1050, what was caused by fine precipitates, unobserved before annealing. Further research on ECAP and effects of the process on precipitation e.g. [24-26], indicates that severe deformation could provide appropriate precipitates distribution and have influence on their size in the microstructure. Particles, especially small, are relatively good obstacles for recrystallization front (migration of HAGB) passing through deformed material. Two contradictory processes occurs, high degree of deformation which favors recrystallization and fragmentation of particles delaying recrystallization. In AA1050 first process is probably dominating, which is caused by low content of alloying elements. Material subjected to rotary swaging and ECAP in [8] was weakened due to recovery and recrystallization, achieving hardness similar to state before defamation after annealing at $350^{\circ} \mathrm{C}$. Higher amount of passes led to greater grain refinement. LAGBs and dislocation substructure became less visible, and HAGBs separated grains. Disorientations distributions approached to purely random texture. Pole figures distinctly showed mainly A-type shear texture fiber, while B-type was less visible. However for both fibers of shear texture some deviations from ideal orientations were obtained, similar like in the case of copper [27]. Ideal orientations describing simple shear in ECAP for fcc materials were described e.g. [28]. Similar results to presented in following article were obtained in [29], high deformation led to homogenization of texture and left mainly shear texture components. Deformation and further annealing at high temperature $\left(350^{\circ} \mathrm{C}\right)$ indicated that recrystallization did not affect the main texture components which were still shear components.

\section{Conclusions}

Investigation of AA1050 subjected to ECAP leaded to following conclusions:

- Accumulated degree of strain have influence on thermal stability. Renewal processes begins at lower temperatures for material subjected to higher deformation.

- After 4 passes through ECAP die, maximum of dislocation density is probably achieved, providing hardness on constant level $53.5 \mathrm{HV}$, for process under described conditions.

- Grain size after ECAP is significantly decreased, achieving the smallest values after 8 passes.

- Material subjected to ECAP after 8 passes and annealed at $350^{\circ} \mathrm{C}$ is characterized by smaller grain size than material after 4 passes and annealing at the same conditions.

- Grain size of homogenized AA1050 is larger than ECAPed and annealed material while both materials achieve similar hardness values equal to $20 \mathrm{HV}$. 
- Initial pass causes inhomogeneity of the texture, while increasing of the passes number lead to homogenization of the texture.

- Annealing of AA1050 does not change the texture. Initial material after homogenizing annealing showed cube texture, after annealing of ECAPed sample, shear texture is retained.

\section{Acknowledgements}

The authors would like to thank Robert Chulist for EBSD measurements. The research was partly supported by grant from National Science Center (NCN): 2012/07/B/ST8/04025.

\section{REFERENCES}

[1] E.O. Hall, Proc. Phys. Soc. 64, 747-753 (1951).

[2] N.J. Petch, J. Iron Steel Inst. 173, 25-28 (1953).

[3] S.J. Yoo, W.J Kim, Korean J. Met. Mater. 49, 104-111 (2011).

[4] R.Z. Valiev, T.G. Langdon, Prog. Mater. Sci. 51, 881-981 (2006).

[5] Y. Saito, H. Utsunomiya, N. Tsuji, T. Sakai, Acta Mater. 47, 579583 (1999)

[6] R.Z. Valiev, R.K. Islamgaliev, I.V. Alexandrov, Prog. Mater. Sci. 45, 103-189 (2000).

[7] T. Szykowny, J. Szczutkowski, Arch. of Foundry 4, 147-154 (2004).

[8] M.A. Abdulstaar, E.A. El-Danaf, N.S. Waluyo, L. Wagner, Mater. Sci. Eng. A 565, 351-358 (2013).

[9] Y. Iwahashi, Z. Horita, M. Nemoto, T.G. Langdon, Acta Mater. 45, 4733-4741 (1997).

[10] S. Ferrasse, V.M. Segal, K.T. Hartwig, R.E. Goforth, J. Mater. Res. 12, 1253-1261 (1997).

[11] R.Z. Valiev, E.V. Kozlov, Y.F. Ivanov, J. Lian, A.A. Nazarov, B. Baudelet, Acta Metall. 42, 2467-2475 (1994).
[12] I. Kim, W.S. Jeong, J. Kim, K.T. Park, D.H. Shin, Scripta Mater. 45, 575-586 (2001).

[13] W.J. Kim, J.K. Kim, W.Y. Chao, S.I. Hong, J.D. Lee, Mater. Lett. 51, 177-182 (2001)

[14] R. Bogucki, K. Sulikowska, M. Bieda, P. Ostachowski, K. Sztwiertnia, Arch. of Met. and Mater. 60, 3063 (2015).

[15] Y. Iwahashi, J. Wang, Z. Horita, M. Nemoto, T.G. Langdon, Scripta Metall. 35, 143-146 (1996).

[16] J. Pospiech, K. Sztwiertnia, F. Haessner, Textures and Microstructures 6, 201-2015 (1986).

[17] K. Sztwiertnia, J. Pospiech, F. Haessner, Textures and Microstructures 12, 233-242 (1990).

[18] Z. Horita, T. Fujinami, M. Nemoto, T.G. Langdon, J. Mater. Process. Technol. 117, 288-292 (2001).

[19] F.J. Humphreys, Acta Mater. 45, 4231-4240 (1997).

[20] A. Oscarsson, B. Hutchinson, B. Nicol, P. Bate, H. Ekström, Mat. Sci. Forum 157-162, 1271-1276 (1994).

[21] D.G. Morris, M.A. Muñoz, Acta Mater. 50, 4047-4060 (2002).

[22] W.Q. Cao, A. Godfrey, W. Liu, Q. Liu, Mater. Lett. 57, 3767-3774 (2003).

[23] R.D. Doherty, D.A. Hughes, F.J. Humphreys, J.J. Jonas, D. Juul Jensen, M.E. Kassner, W.E. King, T.R. McNelley, H.J. McQueen, A.D. Rollett, Mater. Sci. Eng. A 238, 219-274 (1997).

[24] J.K. Kim, H.G. Jeong, S.I. Hong, Y.S. Kim, W.J. Kim, Scripta Mater. 45, 901-907 (2001).

[25] Y.H. Zhao, X.Z. Liao, Z. Jin, R.Z. Valiev, Y.T. Zhu, Acta Mater. 52, 4589-4599 (2004).

[26] C. Xu, Z. Horita, T.G. Langdon, Acta Mater. 55, 203-212 (2006).

[27] S. Li, I.J. Beyerlein, D.J. Alexander, S.C. Vogel, Acta Mater. 53, 2111-2125 (2005).

[28] L.S. Tóth, K.W. Neale, J.J. Jonas, Acta Metall. 37, 2197-2210 (1989).

[29] A.P. Zhilyaev, D.L. Swisher, K. Oh-ishi, T.G. Langdon, T.R. McNelley, Mater. Sci. Eng. A 429, 137-148 (2006). 